Yeast

Yeast 2002; 19: 000-000.

Published online in Wiley InterScience (www.interscience.wiley.com). DOI: 10.1002/yea.916

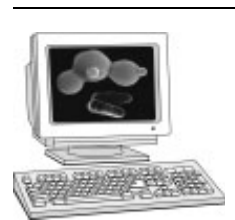

Yeast Functional Analysis Report

\title{
Functional analysis of yeast gene families involved in metabolism of vitamins $B_{1}$ and $B_{6}$
}

\author{
Susana Rodríguez-Navarro, ${ }^{\dagger \dagger \#}$ Bertrand Llorente, 2 T\# María Teresa Rodríguez-Manzaneque, ${ }^{3}$ \\ Anna Ramne, ${ }^{4}$ Genoveva Uber, 'Denis Marchesan, $4 \oint$ Bernard Dujon, ${ }^{2}$ Enrique Herrero, ${ }^{3}$ \\ Per Sunnerhagen ${ }^{4}$ and José E. Pérez-Ortín ${ }^{*}$ \\ I Departamento de Bioquímica y Biología Molecular, Universitat de València, CIDr Moliner 50, E-46100, Burjassot, Spain \\ 2 Unité de Génétique Moléculaire des Levures (URA 2171 du CNRS, UFR 927 Université Pierre et Marie Curie), Institut Pasteur, Paris, France \\ ${ }^{3}$ Departament de Ciències Mèdiques Bàsiques, Facultat de Medicina, Universitat de Lleida, Rovira Roure 44, E-251 98 Lleida, Spain \\ ${ }^{4}$ Department of Cell and Molecular Biology, Lundberg Laboratory, Göteborg University, PO Box 462, S-40530 Göteborg, Sweden
}

*Correspondence to:

José E. Pérez-Ortín,

Departamento de Bioquímica y

Biología Molecular, Universitat de Valéncia, C/Dr Moliner 50,

E-46100, Burjassot, Spain.

E-mail: jose.e.perez@uv.es

$\dagger$ Present address:

Biochemie-Zentrum-Heidelberg

(BZH), Im Neuenheimer Feld

328, D-69/20

Heidelberg, Germany.

\$Present address: Department of Molecular and Cellular Engineering, University of

Pennsylvania School of Medicine, Philadelphia, PA

19104-6160, USA.

I Present address: Department of Microbiology and Institute of Cancer Research, Columbia

University College of Physicians and Surgeons, 701 West 168th

Street, New York, NY

10032, USA.

$\S$ Present address: Department of Medical Biochemistry, Göteborg University, PO Box 440

S-40530 Göteborg, Sweden.

\# These authors contributed equally to this work.

Received: 7 May 2002

Accepted: 30 July 2002

\begin{abstract}
In order to clarify their physiological functions, we have undertaken a characterization of the three-membered gene families $S N Z 1-3$ and $S N O 1-3$. In media lacking vitamin $B_{6}, S N Z 1$ and $S N O 1$ were both required for growth in certain conditions, but neither $S N Z 2, S N Z 3, S N O 2$ nor $S N O 3$ were required. Copies 2 and 3 of the gene products have, in spite of their extremely close sequence similarity, slightly different functions in the cell. We have also found that copies 2 and 3 are activated by the lack of thiamine and that the Snz proteins physically interact with the thiamine biosynthesis Thi5 protein family. Whereas copy 1 is required for conditions in which $B_{6}$ is essential for growth, copies 2 and 3 seem more related with $B_{1}$ biosynthesis during the exponential phase. Copyright $(\subset) 2002$ John Wiley \& Sons, Ltd.
\end{abstract}

Keywords: Saccharomyces cerevisiae; thiamine; pyridoxal; functional analysis; SNZ; SNO 


\section{Introduction}

3 Paralogous gene families, which cover the three

4 domains of life (Galperin, 2001; Goffeau et al.,

5 1996; Henikoff et al., 1997; Rubin et al., 2000)

6 represent an important part of all genomes

7 sequenced so far. They comprise ca. $40 \%$

8 of the yeast genome (Blandin et al., 2000).

9 This gene redundancy can be associated with

10 an exact functional redundancy (Brookfield,

11 1997). Examples are the rDNA genes, the

12 histone genes in species having a rapid early

13 embryonic development, such as the sea urchins

14 (Tartof, 1975) and the CUP1 gene from

15 Saccharomyces cerevisiae. However, in many

16 cases, paralogous genes have undergone functional

17 specializations and are only partially redundant

18 or even functionally non-redundant. The HSP70

19 paralogous gene family of $S$. cerevisiae is an

20 interesting example (Boorstein et al., 1994). On the

21 one hand, some of its members have overlapping

22 functions, such as SSA1, SSA2 and SSA3. None

23 of them is essential, but the triple deletion mutant

24 exhibits a synthetic phenotype and is not viable.

25 On the other hand, other members have acquired

26 essential functions, such as KAR2 and SSCl, although they encode proteins very similar to the Ssa proteins. To obtain an exhaustive overview of these relationships in $S$. cerevisiae, we and others have undertaken a systematic functional characterization of 35 gene families containing two to four members with uncharacterized or poorly characterized functions (Dujon et al., in preparation).

Here we report a study of the $S N Z$ and $S N O$ gene families of $S$. cerevisiae, each consisting of three members (called 1,2 and 3), located adjacently in chromosomes XIII, XIV and VI, respectively (Figure 1). SNO2 and $\mathrm{SNO} 3$ nucleotide sequences are almost identical (99\%), as well as $S N Z 2$ and SNZ3 sequences. SNOI and SNZ1 sequences are more divergent from their respective counterparts (around $81 \%$ identical). Copies 2 and 3 are located within large subtelomeric duplicated regions that encompass other genes, including two members of a family of thiamine (vitamin $\mathrm{B}_{1}$ ) putative biosynthetic enzymes: THIS and THI12. Homologues of $S N Z$ and $S N O$ genes have been found in a wide range of microorganisms and plants (Galperin, 2001; Mittenhuber, 2001), thereby making their functional analysis of general interest. The

\footnotetext{
$1 \mathrm{~kb}$

Figure I. Chromosomal organization of SNZ, SNO and THI5//2 families. Chromosomal regions from chromosomes VI, XIV (both subtelomeric) and XIII, including the gene families, are shown. Genes transcribed in 'Watson' orientation are shown in the upper line and those transcribed from the 'Crick' strand in the lower one. Relevant genes are named. The black bar between chromosomes VI and XIV marks a region of 6350 bp that has only 45 nucleotide changes, mostly single nucleotide transitions. The dotted bars between chromosomes mark regions with partial similarity (50-90\%). Genes THIII and THII 3 (members of the THIS family) are both subtelomeric on chromosomes X and IV, respectively, but do not have neighbouring SNZISNO genes
} 
$1 S N Z$ genes in yeast were originally discovered as

2 expressed in stationary phase (Braun et al., 1996),

3 and the $S N O$ genes were found as proximal and

4 coordinately regulated with the $S N Z$ genes (Padilla

5 et al., 1998). Three different studies have revealed

6 that homologues of the SNZ and SNO genes from

7 Aspergillus nidulans (Osmani et al., 1999), Neu-

8 rospora crassa (Bean et al., 2001) and Cercospora

9 nicotiniae (Ehrenshaft et al., 1999; Ehrenshaft and

10 Daub, 2001) were related to the biosynthesis of

11 pyridoxal (vitamin $\mathrm{B}_{6}$ ).

12 In this study we demonstrate that SNO1 and

13 SNZ1 are required for growth of yeast in the presence of low level of intracellular vitamin $\mathrm{B}_{6} .14$ We also show that transcripts of $S N O 2, S N O 3,15$ $S N Z 2$ and SNZ3 are accumulated in the absence 16 of external thiamine, as well as THI5 and THI11 17 transcripts, and that Snz proteins can interact with 18 Thi5 and Thi12 proteins. 19

Materials and Methods 22

Yeast strains $\quad 24$

The yeast strains used or constructed in this work 25 are listed in Table 1 BY4741, BY4742, CML235 26

Table I. Yeast strains used and constructed

\begin{tabular}{|c|c|c|}
\hline Strain & Genotype & Source or reference \\
\hline FYI679 & $\begin{array}{l}\text { MATa/ } \alpha \text {, ura3-52/ura3-52, leu2- } \Delta \text { //LEU2, trp I- } \\
\text { 63/TRPI, his3- } \Delta 200 / H I S 3\end{array}$ & $\begin{array}{l}\text { Thierry and Dujon, } \\
1992\end{array}$ \\
\hline BY474I & MATa, leu2- $\Delta 0$, his3- $\Delta /$, met I 5- $\Delta 0$, ura3- $\Delta 0$ & Brachmann et al., 1998 \\
\hline BY4742 & MAT $\alpha$, leu2- $\Delta 0$, his3- $\Delta 1$, lys2- $\Delta 0$, ura3- $\Delta 0$ & Brachmann et al., 1998 \\
\hline CML235 & MATa, ura3-52, leu2- $\Delta$ l, his3- $\Delta 200$ & Spore from FY I 679 \\
\hline CML236 & MAT $\alpha$, ura3-52, leu2- $\Delta 1$, his3- $\Delta 200$ & Spore from FY 679 \\
\hline W303-IA & $\begin{array}{l}\text { MATa, ade2-1, leu2-2, 122, ura3-1, his3-II, trpl-I a } \\
\text { can } 100\end{array}$ & H. Ronne \\
\hline PJ69-4a & $\begin{array}{l}\text { MATa, ade2, trp 1-109, leu2-3, I I 2, ura3-52, his3-200 } \\
\text { gal4 } \Delta \text {, gal80 } \Delta, \text { GAL2:ADE2, LYS2::GAL I:HIS3 } \\
\text { met2::GAL7:lacZ }\end{array}$ & et al., 1996 \\
\hline PJ69-4 $\alpha$ & $\begin{array}{l}\text { MAT } \alpha \text {, ade2, trp 1-109, leu2-3, I 12, ura3-52, his3-2 } \\
\text { gal4 } \Delta \text {, gal80 } \Delta, \text { GAL2::ADE2, LYS2::GAL I:HIS3, } \\
\text { met2::GAL7:lacZ }\end{array}$ & et al., 1996 \\
\hline BQSI029 & (BY4742) snzl- $\Delta 0:: L E U 2$ & This work \\
\hline BQSI037 & (BY474I) snzI- $\Delta 0:: M E T I 5$ & This work \\
\hline BQSI067 & (BY474I) snz3- $\Delta 0::$ LEU2 & This work \\
\hline BQSI068 & (BY4742) snz2- $\Delta 0:: U R A 3$ & This work \\
\hline BQS। 48 & 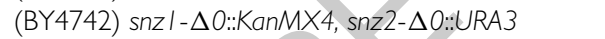 & This work \\
\hline BQSI|49 & 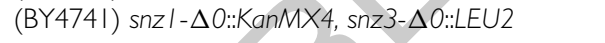 & This work \\
\hline BQSIO60 & (BY4742) snz3- $00::$ LEU2, snz2- $\Delta 0:: U R A 3$ & This work \\
\hline BQSI073 & $\begin{array}{l}(B Y 4742) \text { snz3- } \triangle 0:: \text { LEU2, snz2- } \Delta 0:: U R A 3, \text { snzI - } \\
\Delta 0:: K a n M X 4\end{array}$ & This work \\
\hline FYBLI-8B & MATa, ura3- $\Delta 851$, leu2- $\Delta 1$, his3- $\Delta 200$, lys2- $\Delta 202$ & Fairhead et al., 1996 \\
\hline $\begin{array}{l}\text { FYBLII9- } \\
5 B\end{array}$ & $\begin{array}{l}\text { MAT } \alpha, \text { ura3- } \Delta 851, \text { leu2- } \Delta 1, \text { his3- } \Delta 200, \text { yol055c- } \\
\Delta:: K A N M X 2, \text { ypl258c- } \Delta:: K A N M X 2, \text { yprl } 21 \text { w- } \\
\Delta:: K A N M X 2\end{array}$ & Llorente et al., 1999 \\
\hline $\begin{array}{l}\text { FYBLI- } \\
8 B / B L I 38\end{array}$ & $\begin{array}{l}\text { MATa, ura3- } \Delta 851 \text {, leu2- } \Delta \text { I, his3- } \Delta 200 \text {, lys2- } \Delta 202 \text {, } \\
\text { thi2- } \Delta:: \text { HIS3 }\end{array}$ & Llorente et al., 1999 \\
\hline $\begin{array}{l}\text { FYBLI- } \\
8 B / B L 142\end{array}$ & $\begin{array}{l}\text { MATa, ura3- } \Delta 851 \text {, leu2- } \Delta 1 \text {, his3- } \Delta 200 \text {, lys2- } \Delta 202 \text {, } \\
\text { thi3- } \Delta:: \text { HIS3 }\end{array}$ & Llorente et al., 1999 \\
\hline MML2I & (CML235) snol- $\Delta 0:: K a n M X 4$ & This work \\
\hline MML23 & (CML235) sno2- $\Delta 0:: K a n M \times 4$ & This work \\
\hline MML25 & (CML235) sno3- $\Delta 0:: K a n M X 4$ & This work \\
\hline MML27 & $\begin{array}{l}(\mathrm{CML} 235) \text { sno I- } \Delta 0:: \text { KanMX4 sno2- } \Delta 0:: \mathrm{KanM} \times 4 \\
\text { sno3- } \Delta 0:: \text { KanMX4 }\end{array}$ & This work \\
\hline MML49 & (CML236) snol- $\Delta 0:: K a n M X 4$ sno2- $\Delta 0:: K a n M X 4$ & This work \\
\hline MML50 & (CML236) sno2- $\Delta 0:: K a n M X 4$ sno3- $\Delta 0:: K a n M X 4$ & This work \\
\hline MML259 & (CML235) sno I- $\Delta 0:: K a n M X 4$ sno3- $\Delta 0:: K a n M X 4$ & This work \\
\hline
\end{tabular}


1 and CML236 are the wild-type strains from which

2 the snz and sno mutants were obtained. All

3 strains, except for W303-1A, are from the S288c

4 genetic background.

5

7

8

10

48 The $S$. cerevisiae strains were routinely grown on 49 YPD (1\% yeast extract, $2 \%$ peptone and $2 \%$ glu50 cose), minimal SD medium $[0.67 \%$ yeast nitro51 gen base (YNB without amino acids, DIFCO), $2 \%$ glucose, supplemented with auxotrophic requirements]; or minimal SC medium [0.67\% yeast nitrogen base (YNB without amino acids, DIFCO), $2 \%$ glucose, supplemented with Drop-out mix (DIFCO)]. Vitamin $\mathrm{B}_{6}$-deficient medium (SC-B6) was prepared by substituting the pre-mixed YNB for a mixture of the same components except from vitamin $\mathrm{B}_{6}$ [biotin, pantothenic acid, nicotinic acid, thiamine, inositol, $\mathrm{H}_{3} \mathrm{BO}_{3}, \mathrm{CuSO}_{4}, \mathrm{KI}$, $\mathrm{MnSO}_{4}, \mathrm{NaMoO}_{3}, \mathrm{ZnSO}_{4}, \mathrm{H}_{2} \mathrm{KPO}_{4},(\mathrm{NH})_{2} \mathrm{SO}_{4}$, $\left.\mathrm{MgSO}_{4}, \mathrm{CaCl}_{2}, \mathrm{FeCl}_{3}, \mathrm{Na}_{2} \mathrm{MoO}_{4}\right]$ at the same concentrations as the DIFCO medium in $0.5 \mathrm{M}, \mathrm{pH}$ 6, 2-[N-morpholine]ethanesulphonic acid buffer. For control experiments this medium was supplemented with vitamin $\mathrm{B}_{6}$ to $2 \mu \mathrm{g} / \mathrm{ml}$. For complementation analysis with $\mathrm{pCM}$ plasmids, SCB6 in the absence (derepressing conditions) or in the presence (repressing conditions) of doxycycline was used.

Thiamine-deficient medium was prepared as described (Llorente et al., 1999). It is identical to the $\mathrm{B}_{6}$-deficient medium but without thiamine and plus vitamin $B_{6}$ to $2 \mu \mathrm{g} / \mathrm{ml}$. Geneticin-resistant strains were grown on YPD plates containing $200 \mathrm{mg} / \mathrm{l}$ geneticin (Gibco BRL). Meiosis induction was carried out by growing cells in YPD to saturation and then in YPA ( $1 \%$ yeast extract, $2 \%$ peptone and $2 \%$ acetate) to $2 \times 10^{7}$ cells $/ \mathrm{ml}$. After washing cells twice with water they were resuspended in sporulation medium $(0.5 \%$ potassium acetate).

For phenotypic analysis, the growth of haploid mutants was checked on YP $2 \%$ glycerol and in YPD containing $1.2 \mathrm{M} \mathrm{NaCl}, 0.8 \mathrm{M} \mathrm{KCl}$, or $1.8 \mathrm{M}$ sorbitol. Cells were grown at $15^{\circ} \mathrm{C}, 28^{\circ} \mathrm{C}$ and $37^{\circ} \mathrm{C}$ for $2-3$ days or longer when necessary.

Effects of overexpression of $S N Z 1$ and $S N Z 2 / 3$ genes on growth curves were made after transformation of strain W303-1A to uracil prototrophy with plasmids pCM262SNZ1, pCM262SNZ2 or empty pCM262 vector. At all times before the actual experiment, expression from the $\operatorname{tet}_{7}$ promoter was turned off by the presence of $2 \mu \mathrm{g} / \mathrm{ml}$ doxycycline in the culture medium. To measure growth curves, transformed cells were initially cultivated in liquid SC medium lacking uracil and containing doxycycline. The culture was then split in two aliquots, one of which was rinsed free of doxycycline and then cultured without doxycycline. 100 Growth of cells at $30^{\circ} \mathrm{C}$ in $400 \mu \mathrm{l}$ microchambers 101 with continuous shaking was measured as turbidity 102 
1 in a Labsystems Bioscreen C Microbiology Work-

2 station, using a wide-band visible light filter.

3

4

5 Analysis of sensitivity to menadione

6

7

8

9

17 Isolation of total RNA, electrophoresis, radioactive 18 or non-radioactive probe labelling, hybridization 19 and signal detection were all done as previously 20 described (Llorente et al., 1999; Gallego et al., 21 1997). Probes were generated by PCR amplification from genomic DNA, using oligonucleotides designed to amplify the entire ORF without adjacent sequences (Table 2).
Two-hybrid

A library of genomic $S$. cerevisiae DNA from the his3 ade 2 gal4 strain JB974 in the Gal4 activation domain (Gal4-AD) fusion vector pACT2 (13) was used. The construction of this library will be described elsewhere (Ramne A, Sunnerhagen P et al., in preparation).

Bait clones encoding fusions of Gal4 DNAbinding domains (Gal4-DB) and proteins of interest were constructed using homologueous recombination in vivo (Muhlrad et al., 1992). Briefly, full-length coding sequences of genes were PCR amplified from total genomic S. cerevisiae FY1679 DNA, using the Roche Expand High Fidelity ${ }^{\mathrm{TM}}$ system and hybrid primers with 30 nucleotides of homology to the gene and 17-21 nucleotides of homology to sequences flanking the cloning site (Table 2) of the Gal4-DB vector pGBT9 (Bartel et al., 1993). PCR products were co-transformed with pGBT9 restricted with BamHI and EcoR1

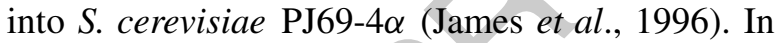
our hands, $>90 \%$ of plasmids from tryptophan prototrophs obtained in this manner contained an insert of the correct size.

Table 2. Oligonucleotide primers used for PCR and cloning

\begin{tabular}{|c|c|}
\hline Name & Sequence $5^{\prime}-3^{\prime}$ \\
\hline 3’pGBT9SNZ2 & AAC AAA GGT CAA AGA CAG TTG ACT GTA TCG CCC AAT TTC GGA AAG TC \\
\hline 5'pGBT9SNZ2 & AAC AAA GGT CAA AGA CAG TTG ACT GTA TCG ATG TCA GAA TTC AAG GTT AAA AC \\
\hline 3’pGBT9SNZI & TAA GAA ATT CGC CCG GAA TTA GCT TGG CTG CCC AAT TTC GGA AAG TC \\
\hline 5'pGBT9SNZI & AAC AAA GGT CAA AGA CAG TTG ACT GTA TCG ATG ACT GGA GAA GAC TIT AAG \\
\hline 3'pCMSNZ2 & C GTA TGG GTA ACC TGG TGA TCC GTC GAC CTG CAG CCA TCC GAT TTC AGA AAG TCT TGC \\
\hline 5'pCMSNZ2 & C CGG ATC AAT TCG GGG GAT CAG गाT AAA CGC GGC CGC ATG TCA GAA TTC AAG GTT AAA AC \\
\hline 3'PCMSNZI & C GTA TGG GTA ACC TGG TGA TCC GTC GAC CTG CAG CCA CCC AAT TTC GGA AAG TC \\
\hline 5'pCMSNZI & C CGG ATC AAT TCG GGG GAT CAG TIT AAA CGC GGC CGC ATG ACT GGA GAA GAC TI AAG \\
\hline SNZI-R & TCA CCC TTG GTA CGA ATC ATA \\
\hline SNZI-D & GGT GGC GTT ATT ATG GAT GT \\
\hline SNOI lo & TTA ATT AGA AAC AAA CTG TC \\
\hline SNOI up & AAC CCA CAG TAC AAT GTC CG \\
\hline SNO2 lo & AGA ACA AAT TCT CTG ATG AA \\
\hline SNO2 up & ATG TCA GAA TTC AAG GTT \\
\hline SNZI lo & TCA CCA CCC AAT TTC GG \\
\hline SNZI up & GGA GAA GAC ПI AAG ATC A \\
\hline SNZ2 lo & CTA CCA TCC GAT TTC AG \\
\hline SNZ2 up & ATG TCA GAA TTC AAG GTT \\
\hline SNZ2sI & ACT ATA ATA GAA AAA TAA GTA TAT CGT AAA AAA GAC AAAA \\
\hline SNZ2s2 & AAG GAA ACA AAT TAG CGT TGT GTG AGC ATC GCT AGT TCTA \\
\hline SNZ2AI & CGA CGG TCA TTT TTG AGA \\
\hline SNZ2A4 & CAT AGT TCA TGA GCC GTT \\
\hline SNZIA & TाT CAT CGA CTT TCC GGA \\
\hline SNZIA4 & TGC CGT TTC AGA TCA TAA \\
\hline SNZIs| & AGC AAA TAT ACA CAG TAC TAA TAT TCA GTT AAT TAT CACG \\
\hline SNZIs2 & AAA GTG TTA TGC TCA AAA TAC CTG TTC AAA GAA ATC ACTG \\
\hline
\end{tabular}


1 Transformants (50-100, picked at random from

2 each transformation) were pooled and used for

3 subsequent mass mating with PJ69-4a transformed

4 with the $S$. cerevisiae genomic DNA Gal4-AD

5 fusion library. Diploid cells with a functional two-

6 hybrid interaction were selected on medium lacking

7 tryptophan, leucine and histidine, and containing

$83 \mathrm{~mm} 3$-aminotriazole (3-AT) and $2 \mathrm{mg} / \mathrm{l}$ adenine.

9 The identity and reading frame of genes in prey

10 plasmids was verified by partial sequencing.

11

12

13

14 Recombinant clones containing SNZ1 or SNZ2

15 open reading frames in the pCM262 plasmid vec-

16 tor were constructed by gap repair (see Table 2)

17 in $S$. cerevisiae similarly to the construction of

18 two-hybrid bait clones. pCM262 is an episomal

19 plasmid derived from pCM190 (Garí et al., 1997),

20 designed to overexpress genes tagged at the C-

21 terminus with three haemaglutinin (HA) epitopes

22 and six histidine residues in tandem, under the

23 control of the $\mathrm{tetO}_{7}$ promoter. The synthetic 3HA-

24 6His cassette was introduced as a PstI-AscI frag-

25 ment in the polylinker of pCM190 (Rodriguez-

26 Manzaneque MT, Herrero E, to be described else-

27 where). After co-transformation into FY1679 of

28 pCM262 (restricted with PstI and Not I) and PCR

29 products containing the respective ORFs, uracil

30 prototrophs were picked and checked for expres-

31 sion of full-length protein product by Western anal-

32 ysis, using anti-HA antibodies. Plasmids were then

33 recovered into $E$. coli from such yeast transfor-

34 mants and the correctness of their restriction pat-

35 terns verified.

36

37

38

\section{Macroarray analysis}

39 We used the hybridization membranes produced by

40 J. Hoheisel (Hauser et al., 1998) and followed his

41 recommendations for use. Briefly, single-stranded

$42 \alpha^{33} \mathrm{P}$ dCTP-radiolabelled complex cDNA samples

43 were synthesized by reverse transcription of the

44 same RNA extracts as for Northern blots. An

45 equimolar mix of the 12 anchored 17-mer oligonu-

46 cleotides $\mathrm{dT}_{15}(\mathrm{~A}, \mathrm{C}, \mathrm{G}) \mathrm{N}$ was used to prime for the

47 reverse transcription reaction. 1/20th of the sam-

48 ple was run on a $5 \%$ denaturing polyacrylamide

49 gel and then exposed for 30 min onto X-ray film

50 (Kodak) to check the efficiency of labelling and the

51 extent of the reverse transcription reaction. Samples that gave good results displayed a smear ranging approximately from 80 to $>600$ nucleotides. The samples were used to hybridize the membranes in the same conditions as for Northern blots. Hybridization signals were revealed with a Phosphorimager (Molecular Dynamics 445SI) after $24 \mathrm{~h}$ exposure. Images were analysed using the XDotsReader program commercialized by COSE. For each hybridization, the intensities were normalized by the mean intensity of the membrane, for comparative purposes. Only genes that showed more than a three-fold increase ratio in the absence of thiamine vs. its presence, and that were differentially expressed in several experiments, were considered.

\section{Results}

Requirement for vitamin $B_{6}$ of the different mutants

The SNZ and SNO homologues SOR1 and PDX2, respectively, from $C$. nicotiniae (Ehrenshaft et al., 1999; Ehrenshaft and Daub 2001) and pyroA from A. nidulans (Osmani et al., 1999) have been described as required for vitamin $\mathrm{B}_{6}$ biosynthesis in those organisms, suggesting that the SNZ and $S N O$ genes could be related to the same pathway in yeast. To check this hypothesis, we constructed all the combinations of single, double and triple deletion mutants for each family. All these mutants grew as well as the control strain on YP or complete synthetic media at either $15^{\circ} \mathrm{C}, 28^{\circ} \mathrm{C}$ or $37^{\circ} \mathrm{C}$ and with glucose or glycerol as sole carbon sources (not shown). Because vitamin $\mathrm{B}_{6}$ is a common compound of standard complete and minimum culture media for yeast, we assayed the growth in a synthetic medium without it. We did not see any major growth defect when the inoculum was precultured in YPD or SC. However, when those cells were pre-grown in SC-B6 medium, single snzl, snol mutants and snz triple mutants showed a strong growth defect (Figure 2A, B, C). This defect was more acute in snzl than in the snol mutant. Neither single snz2, snz3, sno2 or sno3 mutants (not shown) or double $s n z 2$ snz3 mutants showed any growth defects under these conditions. Triple sno mutant behaved similarly to $s n z$ triple mutant (not shown). Defts of the snzl and snol mutants were 100 further analysed with regard to the growth phase 101 of the pre-culture. When the culture time was 102 


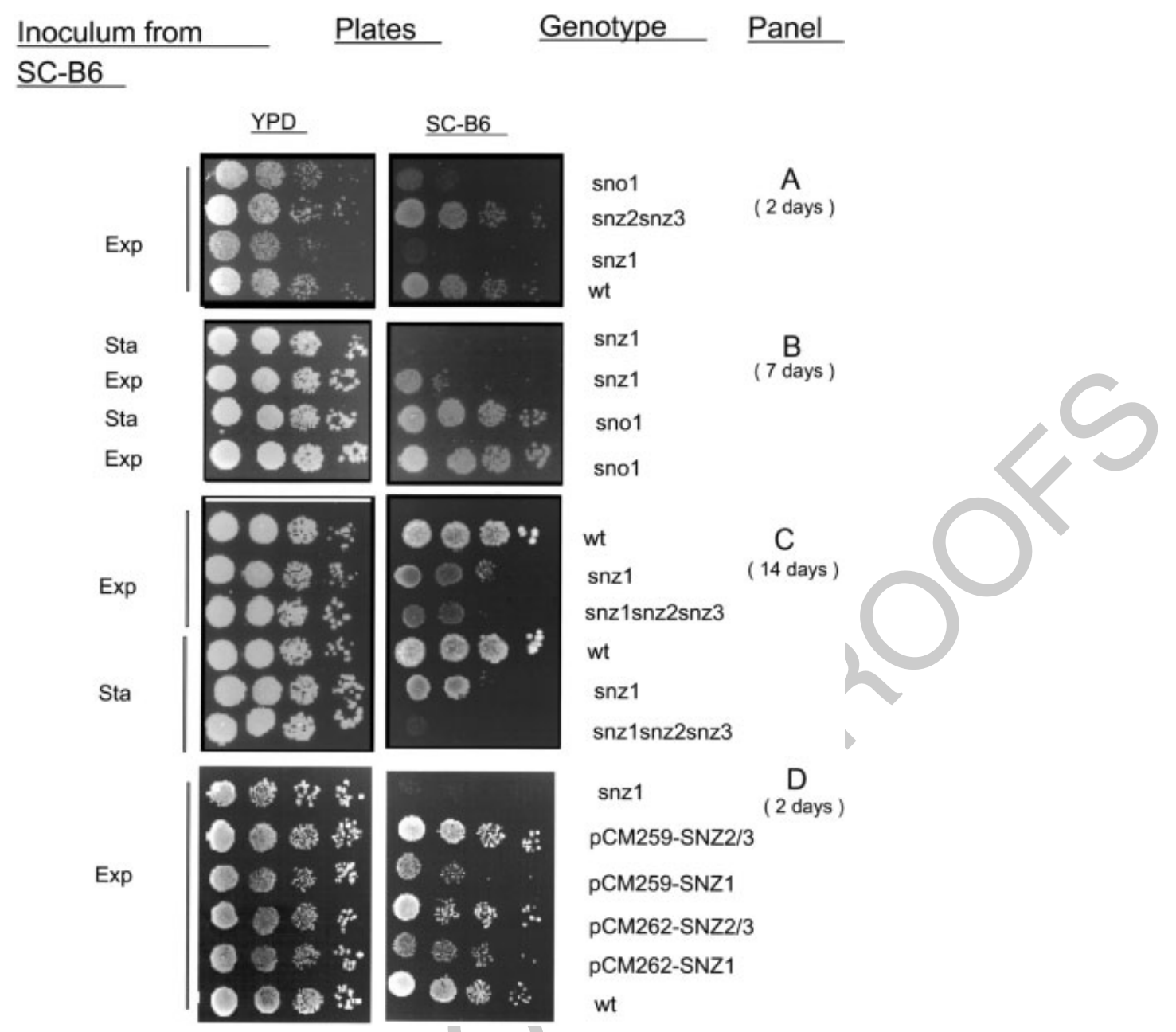

Figure 2. Growth of snz and sno mutant strains in a vitamin $\mathrm{B}_{6}$-lacking medium. Serial four-fold dilutions of exponentially (Exp) or stationary (Sta) phase cultures (inoculum) were spotted on to YPD (control) and SC-B6 plates. Plates were incubated at $28^{\circ} \mathrm{C}$ for 24-36 h (all YPD plates), 2 days [SC plates (A, D)], 7 days [SC plates (B)] or I4 days [SC plates (C)]. Complementation of the auxotrophy for vitamin $B_{6}$ in the snzl mutant by a PCM259/262-SNZI or pCM259/262-SNZ2 plasmids is shown in (D). Two independent transformants for each plasmid are shown. The relevant genetic background of the strains is indicated

1 extended to 7 days, the snzl mutant was more

2 severely defective than the snol mutant and the

3 defect worsened if the preculture proceeded from

4 stationary phase (Figure 2B). Although, at first

5 sight, the triple mutant snzl snz2 snz3 behaved

6 identically to the single snzl mutant (not shown),

7 very long incubation times (2 weeks, Figure 2C)

8 revealed a stronger growth defect for the triple

9 mutant. It is worth noting that the growth level seen

10 in YPD control plates is similar for the wild-type

11 and for all the mutants tested, suggesting that the

12 viability of the cells is unaffected by the absence

13 of those gene products during stationary phase.
The growth defect of snzl mutant can be 14 complemented by the overexpression of both SNZ1 15 and SNZ2 (see Figure 2D). This result suggests that 16 SNZ2 and SNZ3 code for a protein with a sim- 17 ilar activity to Snzlp. As expected, the addition 18 of vitamin $\mathrm{B}_{6}$ alone also restores the growth (data 19 not shown).

In conclusion, $S N Z 1$ and $S N O 1$ are both required for growth when cells are depleted in vitamin $\mathrm{B}_{6}$. The residual growth in SC-B6 observed for snzl snz2 snz3 triple mutants pre-cultured until the exponential phase probably reflects traces of vitamin $\mathrm{B}_{6}$ in the cells. On the other hand, SNZ2
4 15 6 7 18 


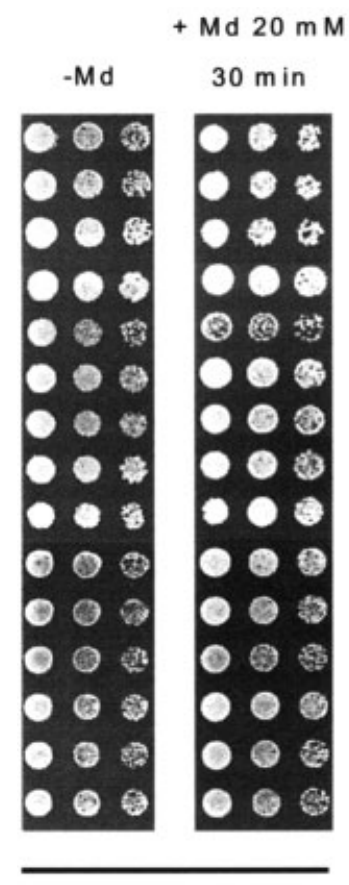

exponential
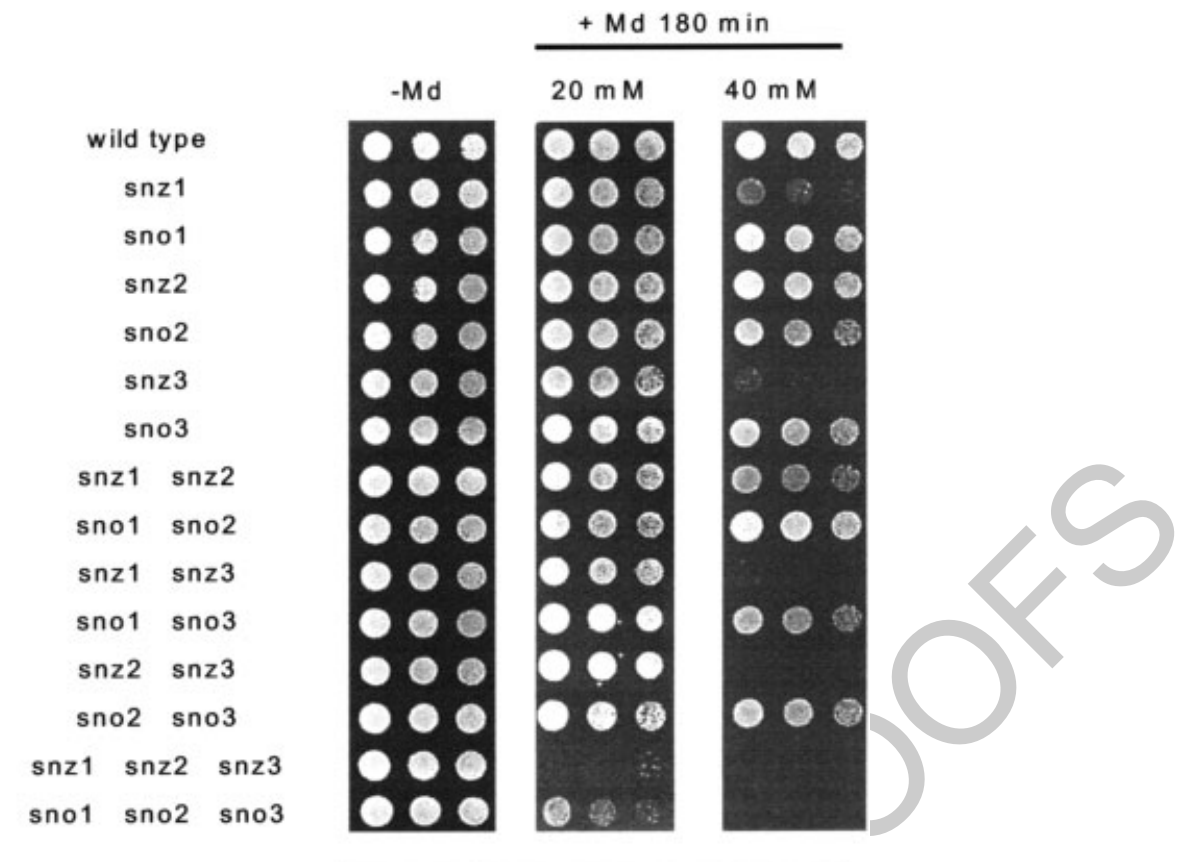

post-diauxic

Figure 3. Menadione sensitivity of snz and sno mutant strains. Sensitivity of snz and sno mutants to menadione treatment. Cells were grown in YPD medium at $30^{\circ} \mathrm{C}$, to either exponential phase $\left(2 \times 10^{7} \mathrm{cells} / \mathrm{ml}\right)$ or $20 \mathrm{~h}$ later (post-diauxic phase) and were treated with the indicated menadione concentrations for $30 \mathrm{~min}$ (exponential cells) or 180 min (post-diauxic cells). After treatments, cells were diluted in fresh YPD medium ( I 5 serial dilutions) and $2 \mu$ l drops were spotted on YPD plates. Growth was recorded after 2 days of incubation at $30^{\circ} \mathrm{C}$. The apparent higher resistance of the snzl snz2 mutant compared with snz I single mutant is due to a higher cell number in this particular experiment. It was not observed in other experiments

1 and SNZ3 have no complete functional redundancy

2 with $S N Z 1$, despite similar biochemical properties 3 of their products.

4

5

6

\section{Menadione sensitivity}

7 It has been shown previously that some of the

$8 \mathrm{snz}$ and sno mutants are sensitive to methylene

9 blue, a generator of singlet oxygen (Padilla et al.,

10 1998), one of the most active ROS (reactive oxygen

11 species). Similarly, the SNZ-homologous genes

12 pyroA and SORI genes are known to protect $A$.

13 nidulans and $C$. nicotiniae, respectively, against

14 singlet oxygen (Ehrenshaft et al., 1999; Osmani 15 et al., 1999).

16 We tested the sensitivity of snz and sno mutants

17 to the superoxide generator, menadione. Mena-

18 dione sensitivities of all the mutants were similar

19 to that of the control strain when treated during the

20 exponential phase for 30 min (Figure 3) or longer (not shown). However, when treated during the post-diauxic phase for $180 \mathrm{~min}$ with $20 \mathrm{mM}$ menadione, the triple sno1 sno2 sno3 and, especially, snzl snz2 snz 3 mutants, were extremely sensitive to it. By using a higher drug concentration $(40 \mathrm{mM})$ it was possible to observe that the single $s n z 1$ or $s n z 3$ and, not surprisingly, the double snzl snz3 and $s n z 2 s n z 3$ mutants were more sensitive than other single or double mutants. All mutants, as well as wild-type cells, were highly resistant to both drug concentrations when treated during the stationary phase (not shown).

These results confirm that $S N O$, and especially $S N Z$ genes, confer resistance to ROS to the cells. These results also show that the protection effect is more dependent on $S N Z 1$ and, surprisingly, $S N Z 3$ than on $S N Z 2$, and that this effect is masked by the intrinsic resistance of advanced stationary cells to environmental stresses (Werner-Washburne et al., 1996). 


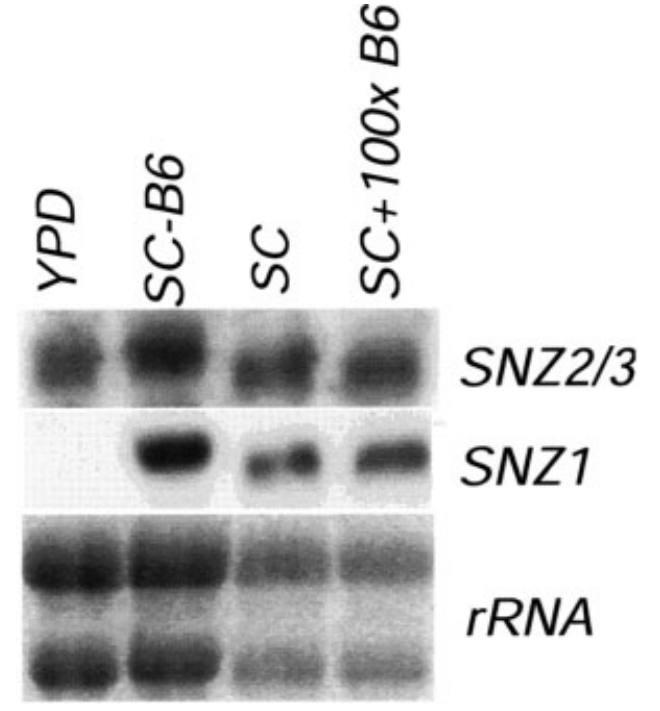

Figure 4. Influence of vitamin $B_{6}$ in SNZ expression. Total RNA from log phase cultures in YPD, SC (vitamin $B_{6}$ is $2 \mu \mathrm{g} / \mathrm{ml}), \mathrm{SC}-\mathrm{B}_{6}$ and $\mathrm{SC}+\mathrm{B}_{6}$ (vitamin $\mathrm{B}_{6}$ is $0.2 \mathrm{mg} / \mathrm{ml}$ ) was analysed in a wild-type strain with a Northern experiment using SNZI and SNZ2/3 probes (made with oligonucleotides SNZ2AI and SNZ2A4). Total rRNA is included as loading control

\section{Vitamin $B_{6}$ effects on expression of $S N Z$ genes}

2 evernight cultures into fresh medir sumption of logarithmic growth occurred to $16 \mathrm{~h}$ later than for cells not overexpressing either protein. This effect was clearly stronger for the Snz2 fusion protein (Figure 5C) than for Snz1p (not shown). Once logarithmic growth had resumed, only a minor effect on growth rate was seen after the longest periods in stationary phase. Density at saturation was also largely unaffected. As can be seen (Figure 5D), this effect is clearly dependent on gene expression: at a high concentration of doxycycline, $2 \mu \mathrm{g} / \mathrm{ml}$ (transcription repressed), no delay was observed. At intermediate concentrations $(0.05$ or $0.5 \mu \mathrm{g} / \mathrm{ml})$, the delay was less pronounced (not shown). The addition of vitamin $\mathrm{B}_{6}$ at any stage of the experiment did not change the results (not shown).

\section{Two-hybrid screens}

In order to find more clues to the specific roles of SNZ genes, we conducted two-hybrid screens. In the first one, with the $S N Z 1$ bait, out of 10 positive clones obtained that encoded bona fide in-frame proteins, three contained sequences of the YHR198c ORF. These represented two independent clones with a common overlapping segment, encoding a short central portion of the Yhr198c protein (amino acids 167-180).

When SNZ2 was used as the bait, YJR156c (THI11) was found as reactive prey in the correct reading frame. The THIII gene product is probably involved in the biosynthesis of the pyrimidine precursor of thiamine (Hohmann and Meacock, 1998), and it is homologous to the Schizosaccharomyces pombe Nmt1 protein (Van Dyck et al., 1995). Thil1p has three paralogues in the yeast genome, with almost identical sequences, Thi5p, Thi12p and Thi13p. In similar screens using SNO1 or $S N O 2 / 3$ as baits, no preys were found that corresponded to proteins involved in vitamin biosynthesis (not shown).

\section{Vitamin $B_{\mid}$effects on gene expression}

The close proximity on chromosomes VI and XIV of the putative thiamine biosynthetic genes THI5 and THI12, respectively, to the SNZ3/SNO3 and SNZ2/SNO2 loci (see Figure 1) together with the results of our two-hybrid experiments (see above) may suggest a possible functional link between these two classes of genes. Therefore, we investigated the effects of vitamin $B_{1}$ depletion on the 100 transcription of the $S N Z$ and $S N O$ families, and on 101 the prototrophy of the corresponding null mutants. 102 


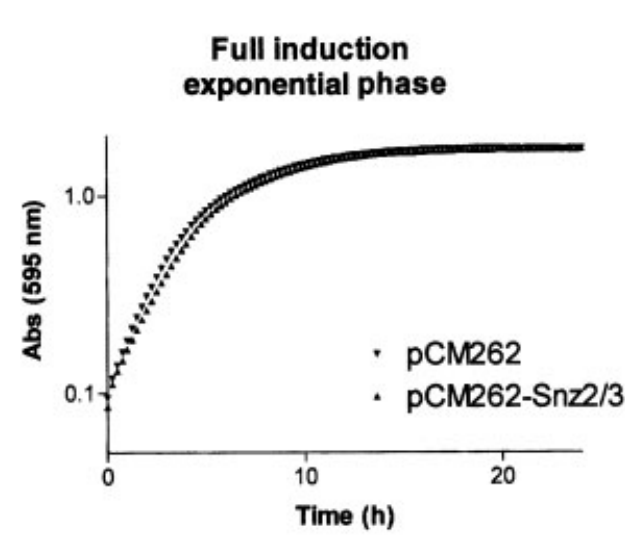

Full induction $16 \mathrm{~h}$ in stationary phase

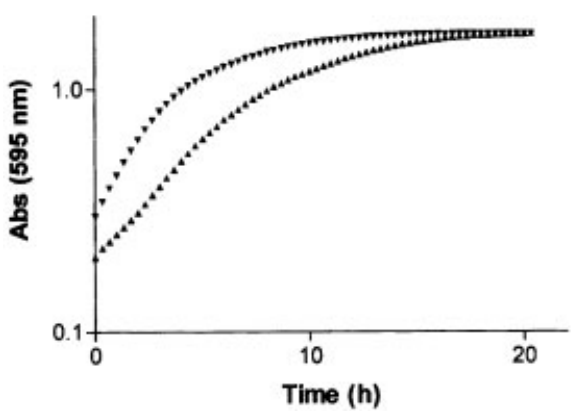

A

Full induction $36 \mathrm{~h}$ in stationary phase

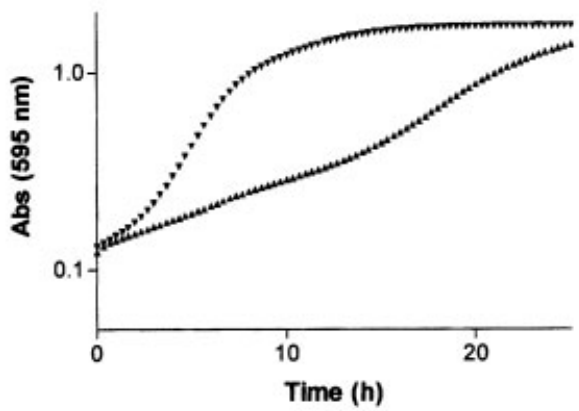

B

C

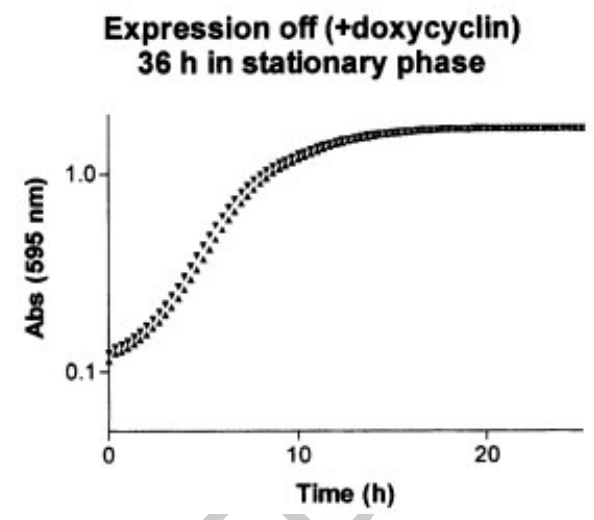

Figure 5. Growth of SNZ2 overexpressing strains after dilution in fresh medium. W303-IA cells transformed with empty vector PCM262 (inverted triangles), PCM262-SNZI (not shown), or PCM262-SNZ2 (triangles) were grown in liquid SC - ura medium in the presence or absence of $2 \mu \mathrm{g} / \mathrm{ml}$ doxycycline, as indicated in Materials and methods. From the logarithmic pre-culture $\left(A_{600}=0.5\right)$, the cells were either transferred directly $(A)$, or allowed to proceed to stationary phase (B, C, D). For $B, C$ and $D$, cells were then kept for the indicated times at stationary phase. Next, the cell suspension was diluted to $O D=0.1$ in fresh medium (with or without doxycycline, as indicated), and growth with shaking and aeration in $400 \mu \mathrm{l}$ chambers was recorded. Values are the mean of two independent experiments; for clarity, error bars are omitted. Absorbance values ( $y$ axis) are shown on a logarithmic scale

1 It is known that the concentration of exogenous

2 thiamine influences the transcript amounts of

3 several genes involved in its metabolism, such

4 as THI4, 5, 6, 10, 11, 12, 13, 20, 21, 22

5 and $\mathrm{PHO3.} \mathrm{Moreover,} \mathrm{this} \mathrm{regulation} \mathrm{is} \mathrm{under}$

6 the positive control of one or both of the

7 two regulators Thi2p and Thi3p (Hohmann and

8 Meacock, 1998). In order to have an exhaustive

9 list of genes whose transcripts are regulated by

10 the extracellular concentration of thiamine, we used

11 macroarrays of genes produced by the J. Hoheisel

12 laboratory (Hauser et al., 1998). Hybridizations

13 were performed using complex cDNA samples

14 synthesized from RNAs of the wild-type strain

15 FYBL1-8B, grown in the presence of high

16 concentration of extracellular thiamine $(1 \mu \mathrm{M})$ and in the absence of extracellular thiamine. We also performed hybridizations using complex cDNA samples synthesized from RNAs of the strains FYBL138 and FYBL142 deleted for THI2 and $T H I 3$, respectively, grown in the presence of low concentration of extracellular thiamine $\left(10^{-2} \mu \mathrm{M}\right)$. All the genes we found to be upregulated in the absence of exogenous thiamine are indicated in Table 3. We confirmed the already published upregulation of THI4, 5, 6, 10,11,12, 13, 20,21, 22, PET18, YLROO4C and PHO3. But, in addition, we found that transcripts of $S N O 2 / 3, S N Z 2 / 3, T H I 2$ and ECM15 also accumulated in the absence of exogenous thiamine. Since Thi2p and Thi3p do not regulate the transcription of ECM15, this gene has not been studied further. The accumulation of the 
Table 3. Yeast transcripts regulated by extracellular thiamine

\begin{tabular}{|c|c|c|c|c|c|c|}
\hline Genes & & Induction & $\Delta$ thi2 & $\Delta$ thi3 & Northern & Conclusion \\
\hline YNL332W & THII 2 & +++ & - & - & NT & Confirmation \\
\hline$Y J R / 56 c$ & THIII & +++ & + & - & NT & Confirmation \\
\hline YDL244w & THII 3 & +++ & + & - & NT & Confirmation \\
\hline YFL058W & THI5 & +++ & + & - & NT & Confirmation \\
\hline YAR07 I w & PHOII & +++ & - & - & NT & Confirmation \\
\hline YHR2 I $5 \mathrm{~W}$ & $\mathrm{PHO} / 2$ & +++ & - & - & NT & Confirmation \\
\hline YBR092C & $\mathrm{PHO} 3$ & +++ & - & - & NT & Confirmation \\
\hline YBR093C & $\mathrm{PHO5}$ & +++ & - & - & NT & Confirmation \\
\hline YLR237w & THIIO & +++ & +++ & - & NT & Confirmation \\
\hline YGRI $44 w$ & THI4 & +++ & + & + & NT & Confirmation \\
\hline YPL214C & THI6 & +++ & - & + & NT & Confirmation \\
\hline YNL334C & SNO2 & +++ & - & - & Yes & New \\
\hline YFL060c & SNO3 & +++ & - & - & Yes & New \\
\hline YNL333w & SNZ2 & +++ & - & - & Yes & New \\
\hline YFL059w & SNZ3 & +++ & - & - & Yes & New \\
\hline YOLO55c & THI2O & +++ & - & - & Yes & Confirmation \\
\hline YPL258c & THI2I & +++ & - & - & Yes & Confirmation \\
\hline YPR / $2 / W$ & THI22 & +++ & - & - & Yes & Confirmation \\
\hline YCRO20c & PETI8 & +++ & - & - & Yes & Confirmation \\
\hline YLR004c & & +++ & - & - & Yes & Confirmation \\
\hline YBR240c & THI2 & +++ & & - & Yes & New \\
\hline YBLOO/C & ECMI5 & +++ & +++ & +++ & & New \\
\hline
\end{tabular}

This table indicates the results from macroarray hybridization experiments. The Induction column represents the relative levels of transcripts observed for the wild-type strain FYBLI-8B grown in the absence of extracellular thiamine with respect to those found in the presence of extracellular thiamine (only ratios above or equal to a three-fold increase have been considered). Columns $\Delta$ thi 2 and $\Delta$ thi3 represent the same ratios but for the strains FYBLI38 and FYBLI 42 deleted for $T H I 2$ and $T H I 3$, respectively. These strains are auxotrophic for thiamine and have thus been grown in the presence of a low extracellular thiamine concentration $\left(10^{-8} \mathrm{M}\right)$ instead of no thiamine. 'Yes' indicates that the regulation has been confirmed by Northern blot experiments. NT, non-tested by Northern blot experiment.

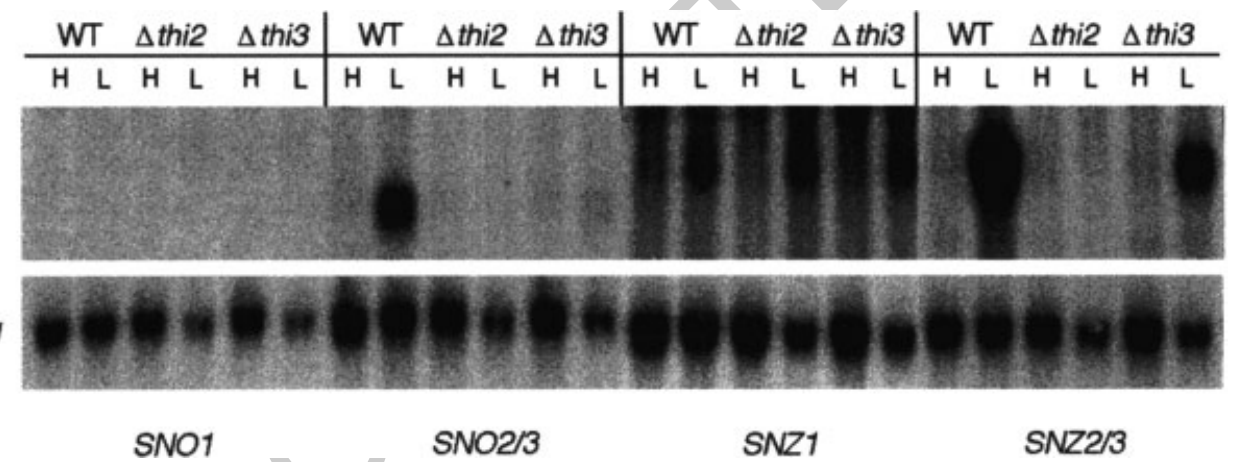

Figure 6. Gene expression analysis in thiamine-limiting conditions. $10 \mu \mathrm{g}$ total RNA extracted from cells grown in SC to exponential phase in the presence of high $(\mathrm{H})$ or low $(\mathrm{L})$ extracellular thiamine concentration were loaded and run on a $1.5 \%$ agarose gel containing $0.6 \%$ formaldehyde, transferred to Hybond $\mathrm{N}^{+}$membranes (Amersham) and hybridized with specific probes (upper panel; made by PCR with oligonucleotide pairs called 'lo' and 'up' for each case; see Table 2) indicated at the bottom of the figure. $\mathrm{H}, \mathrm{I} \mu \mathrm{M}$ extracellular thiamine; $\mathrm{L}$, no thiamine for the wild-type strain (WT) FYBLI-8B, and $10^{-2} \mu \mathrm{M}$ for the auxotrophic strains $\triangle$ thi2 (FYBLI-8B/BLI38) and $\Delta$ thi3 (FYBLI-8B/BLI42). ACTI was used as loading control for all the samples

1 other transcripts is dependent on the presence of

2 either Thi2p or Thi3p or both. These results were

3 confirmed by Northern blot experiments, as shown in Figure 6 for $S N O 2 / 3$ and $S N Z 2 / 3$. Other known examples of thiamine regulation, such as $P D C 5$ and PDCl (Muller et al., 1999), are not listed
4 5 6 
1 here because of the very stringent criteria used for

2 significance levels (see Materials and methods) but

3 were detected as induced by Northern blot. It is

4 impossible to conclude whether both the transcripts

5 of $\mathrm{SNO}_{2}$ and $\mathrm{SNO} 3$ are regulated in the same

6 way because their nucleotide sequences are nearly

7 identical, which must generate cross-hybridization.

8 This is also the case for $S N Z 2$ and $S N Z 3$, as well

9 as for the $P H O$ gene family, of which only the

10 transcripts of $\mathrm{PHO} 3$ have been described as being

11 regulated by extracellular thiamine concentration

12 (Nishimura et al., 1992).

13 The Northern blot experiments shown in Figure 6

14 illustrate that the SNO1 transcripts are unde-

15 tectable with this approach during exponential

16 growth phase, and remain unaffected by the extra-

17 cellular concentration of thiamine. SNO2-3 tran-

18 scripts are detectable during the exponential growth

19 phase only in the absence of extracellular thiamine,

20 in a THI2-3-dependent manner. SNZ1 transcripts

21 are slightly more abundant during the exponential

22 growth phase in the presence of low concentra-

23 tion of extracellular thiamine with respect to high

24 concentration, but this accumulation is not depen-

25 dent on either Thi2p or Thi3p. SNZ2-3 transcripts

26 accumulation occurs clearly in the absence of extra-

27 cellular thiamine, and is completely dependent on

28 Thi2p and only partially dependent on Thi3p.

29

30

31

32

33

34

35 Most microorganisms and plants possess at least

36 one pathway leading to pyridoxine and pyridoxal

37 5'-phosphate synthesis. The Escherichia coli path-

38 way has been extensively studied (see Drewke and

39 Leistner, 2001) but the corresponding pathway in

40 yeast is not well defined. Nevertheless, the fact that

41 the L-[amide- ${ }^{15} \mathrm{~N}$ ]glutamine label is incorporated

42 efficiently into pyridoxine in $S$. cerevisiae but not

43 in $E$. coli indicates that vitamin $\mathrm{B}_{6}$ biosynthesis

44 must be significantly different in either organism

45 (Tazuya et al., 1995).

46 Other eukaryotic organisms, such as $A$. nidu-

47 lans, Mucor racemosus and N. crassa and prokary-

48 otes, such as Staphylococcus aureus and Bacillus

49 subtilis, may have biosynthetic pathways for pyri-

50 doxine similar to that of $S$. cerevisiae (Tanaka

51 et al., 2000). It has recently been shown that the
pyroA gene from A. nidulans (Osmani et al., 1999) and the PDX1 (SOR1) gene from C. nicotiniae (Ehrenshaft et al., 1999) are involved in de novo biosynthesis of vitamin $\mathrm{B}_{6}$ in those fungi. It has been suggested that mutations in $p d x-1$ and $p d x$ 2 (SNZ and SNO homologues, respectively) cause pyridoxine auxotrophy in $N$. crassa (Bean et al., 2001). A more recent study shows an involvement of PDX2 of $C$. nicotianae in the pyridoxine biosynthesis pathway (Ehrenshaft and Daub, 2001). The fungal genes are 58-67\% (SNZ) and 36-38\% $(S N O)$ identical to the yeast genes. The $S N Z$ and $S N O$ families are widely represented in eubacteria, archaea and eukaryotes (Braun et al., 1996; Ehrenshaft et al., 1999; Galperin, 2001; Mittenhuber, 2001). Our results indicate that the SNZ and $S N O$ gene families are also involved in the vitamin $\mathrm{B}_{6}$ biosynthesis in $S$. cerevisiae. We identified a functional specialization within these two gene families, since the absence of copy 1 leads to a more severe growth phenotype than the absence of copy 2 and 3 when cells are grown in SC-B6. Although the SNZ2-3 genes seem to be dispensable for any condition tested, they should code for proteins with a similar activity to Snzlp because they can complement, at least as efficiently as $S N Z 1$ itself (Figure 2D), the snzl null phenotype when overexpressed. This suggests that all the three $S N Z$ genes code for enzymes involved in vitamin $\mathrm{B}_{6}$ biosynthesis, probably at the last step, the ring closure, as suggested byEhrenshaft et al. (1999). Vitamin $\mathrm{B}_{6}$, however, seems not to be a regulator of $S N Z$ gene transcription (Figure 4), although the high transcription levels already present in synthetic medium might mask the effect of the absence of the vitamin.

The phenotypes of sno mutants are less pronounced than that of the corresponding snz mutants. It has been suggested that $S N O$ genes are involved in the first step of pyridoxal biosynthesis (Ehrenshaft and Daub, 2001; Osmani et al., 1999). Thus, it is conceivable that, if the SNZ genes code for pyridoxine biosynthetic enzymes, the substrate for Snz proteins could be produced in the absence of Sno proteins, although in very minor amounts, by alternative pathways.

$S N Z$ and SNO genes have an interesting effect on sensitivity to oxidative radicals. Padilla et al. (1998) have shown that snol or snzl mutations 100 are very sensitive to the singlet oxygen generator 101 methylene blue. Furthermore, it has been shown 102 
1 that $\mathrm{B}_{6}$ vitamers are efficient quenchers of sin-

2 glet oxygen in vitro (Bilski et al., 2000; Ehrenshaft

3 and Daub, 2001) and that externally added vitamin

$4 \mathrm{~B}_{6}$ effectively suppresses the toxicity of methy-

5 lene blue in A. nidulans (Osmani et al., 1999). We

6 have shown here that a different kind of ROS, the

7 superoxide radical, produced by menadione, has

8 a similar effect on $s n z / s n o$ mutants. It has been

9 argued that $\mathrm{B}_{6}$ can act in active oxygen resistance

10 and that such as a protective effect is more neces-

11 sary in stationary phase, when cells are subjected to

12 increased oxidative stress (Ehrenshaft et al., 1999).

13 Vitamin $\mathrm{B}_{6}$ may be just an antioxidant or, per-

14 haps, its destruction by ROS causes deficiency of

$15 \mathrm{~B}_{6}$ vitamers that are necessary for other metabolic

16 uses (Osmani et al., 1999). This last hypothesis

17 is supported by the fact that neither $\mathrm{H}_{2} \mathrm{O}_{2}$ nor

18 menadione induce the transcription of any of these

19 genes (Gasch et al., 2000). Furthermore, prelim-

20 inary data from the groups of Joaquim Ros and

21 Enrique Herrero (University of Lleida, Spain) indi-

22 cate that addition of vitamin $B_{6}$ reduces the level

23 of protein carbonylation (a parameter measuring

24 protein oxidation) induced by addition of oxidants

25 such as menadione or hydrogen peroxide. Finally,

26 the striking difference between menadione sensitiv-

27 ity of $s n z 2$ and $s n z 3$ (see Figure 3) suggests that

28 the two genes have somewhat different roles, in

29 spite of their high sequence similarity.

30

31

32

33 It is known that in some prokaryotes (e.g. E.

34 coli), some precursors and enzymes (e.g. the $p d x K$

35 gene product) are shared by biosynthetic path-

36 ways for the vitamins $\mathrm{B}_{1}$ and $\mathrm{B}_{6}$ (Begley et al.,

37 1999; Mittenhuber, 2001). In S. cerevisiae the fact

38 that the transcription of the SNZ2-3 and SNO2-3

39 genes is induced by the absence of thiamine in a

40 Thi2p/Thi3p-dependent manner, suggests that those

41 genes have a function related with the biosynthesis

42 of vitamin $B_{1}$ as well. Two additional facts support

43 this view.

44 First, the finding of interactions between Thi and

$45 \mathrm{Snz}$ proteins by two-hybrid analysis (see below)

46 provides an independent suggestion for a common

47 functional pathway for Snz and Thi proteins, i.e.

48 a putative role for the Snz, and also Sno, proteins

49 in thiamine biosynthesis, and corroborates the idea

50 of Hohmann and Meacock (1998). Our results sug-

51 gest, however, that Snz2-3 and Sno2-3 proteins, but not Snz1p and Sno1p, are related to vitamin $\mathrm{B}_{1}$ biosynthesis: SNZ1 and SNO1 transcription is not induced by thiamine depletion. Although all the members of Snz and Sno protein families can reasonably be considered as putative enzymes acting on the same reactions, it cannot be dismissed that they may act at different times or cellular compartments, similarly to other cases of isoenzymes (Matthews et al., 2000). Several pathways for thiamine biosynthesis should exist because none of the single, double and triple deletion mutants of the $S N O$ and the $S N Z$ gene families display auxotrophy for thiamine (Llorente B, Peréz-Ortín, not shown). This is consistent with the fact that under anaerobic conditions the pyrimidine moiety of thiamine is not derived from pyridoxal, therefore a different pathway must act instead (Tanaka et al., 2000).

Second, there is close map proximity between these genes and some members of the THI5/11/12/ 13 family (see Figure 1). These THI genes are highly similar: the proteins differ only in one amino acid out of 340 . The corresponding protein is only detected in the absence of thiamine (Muller et al., 1999), THI5 and THII2 transcripts accumulate in the absence of extracellular thiamine (Meacock PA, personal communication) and they putatively code for an enzyme involved in the biosynthesis of the pyrimidine moiety of the thiamine molecule (Hohmann and Meacock, 1998). It is therefore interesting that three consecutive genes repeated twice in the genome have a common transcriptional response. The three couples SNO/SNZ share divergently transcribed promoters, something that supports the notion of common regulatory sequences (Padilla et al., 1998). This headto-head arrangement has been also found in the yeasts Candida albicans and S. kluivery (Llorente $\mathrm{B}$, unpublished), in the fungus $N$. crassa (Bean et al., 2001), and in the sponge Suberites domunculata (Seack et al., 2001) that suggests an ancient origin for $S N O-S N Z$ co-regulation. The close association of THI genes with SNZ-SNO, however, is not so common. We have analysed the genomes of Schizosaccharomyces pombe, Candida albicans and the hemiascomycetes group of the Genolevures project (Souciet et al., 2000). Most of them possess only one orthologue of SNZ, SNO and THI5. None of the THI5 orthologues has been found to be syntenic with the SNO-SNZ orthologues. In addition, 100 copies 2 and 3 of the SNZ-SNO genes seem to be 101 the product of a recent subtelomeric chromosome 102 
1 duplication, since they are not detected in some $S$.

2 cerevisiae strains (Padilla et al., 1998). The func-

3 tional specialization of copies 2 and 3 and their

4 association with THI5 locus may thus have devel-

5 oped recently.

6

\section{7}

9

\section{A protein complex of Snz, Sno and Thi proteins}

As discussed above, our two-hybrid results show that Snz1p interacts with Yhr198p and Snz2/3p with Thi11p. Previous two-hybrid analysis showed interactions between the Snz and Sno proteins themselves and with other proteins (DIP database, 2001; Ito et al., 2000; Padilla et al., 1998; Uetz et al., 2000). A scheme of the putative interactions is shown in Figure 7.

Examples of multi-enzymatic complexes comprising enzymes that catalyse successive steps in a metabolic pathway are well known (Matthews et al., 2000). It seems that every one of the Snz and Sno proteins can interact with itself and with the other members. Because the transcription profiles of copies 2 and 3, on one hand, and copy 1 , on the other hand, are so different that it is possible that the protein complex changes depending on the physiological circumstances of the cell. In fact, Padilla et al. (1998) described a $230 \mathrm{kDa}$ complex dependent on Snz1p and which only appears during stationary phase. Because the predicted molecular weight for these proteins is between $25 \mathrm{kDa}$ (Sno) and $32 \mathrm{kDa}(\mathrm{Snz})$, the complex found should include several copies of them and/or additional proteins. The two-hybrid experiments show candidates for those interacting proteins.

The first candidate is Yhr198p. No definitive function has yet been assigned to YHR198c, but it carries a purine/pyrimidine phosphoribosyl

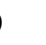

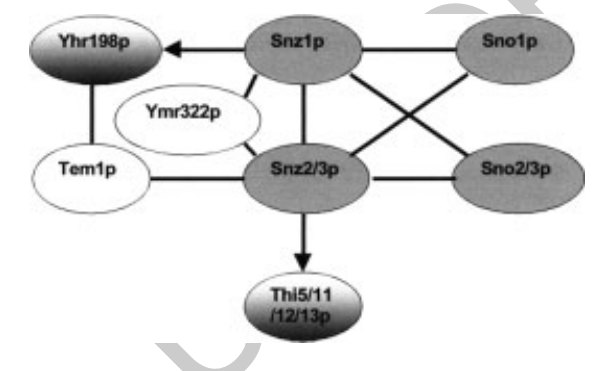

Figure 7. Summary of two-hybrid interactions of Snz, Sno and Thi families. Protein preys detected in this work are represented in degraded grey. Interacting proteins a linked by bars and arrows. Sno and Snz proteins are highlighted. See text for further discussion transferase signature, indicative of a role in the purine/pyrimidine salvage pathway. It has been described to interact with Temlp by two-hybrid analysis which itself, in turn, interacts with Snz2/3p (Uetz et al., 2000). Another protein that has been described to interact with the Sno-Snz proteins is Ymr322p (DIP database, 2001).

The existence of a multiprotein complex is also supported by our overexpression studies. We found that Snz1p and, specifically, Snz2p when overexpressed as 3HA-6His-tagged fusions in a nonregulated way, caused a delay in the recovery from the stationary phase. The most direct explanation for the delay is that some metabolite(s) that are exhausted during this phase but necessary to resume growth are, in this condition, more difficult to synthesize. However, the supplementary addition of the obvious candidate, pyridoxal, does not reduce the delay (Sunnerhagen $\mathrm{P}$, not shown). Furthermore, the delay occurred after growth in standard (i.e. not vitamin-depleted medium). The defect caused by extra copies of tagged Snz proteins may be caused by an imbalance of the protein subunits of the complex due to of the withdrawal of some important subunit(s), which is caused by the excess subunits of $\mathrm{Snz}$ protein or by the 3HA tag. It has been argued that an imbalance between the putative subunits of the complex explains the dominant-negative effect of the snz $1-\Delta 2$ mutation in 6-AU sensitivity (Padilla et al., 1998).

In summary, our results show that these two families, $S N Z$ and $S N O$, contain genes that are only partially redundant in function in spite of their high sequence similarity. This seems to be another case in which gene duplicates have different roles in yeast (Blandin et al., 2000; Brookfield, 1997; Llorente et al., 1999).

\section{Acknowledgements}

We thank Dr J. Hoheisel for the gift of yeast macroarrays, Dr S. Hohmann for his critical reading of the manuscript and A. Llopis for her excellent technical work. B.D. is a member of the Institut Universitaire de France. This work was funded by the European Commission as part of the Eurofan 2 project under contract BIO4-CT97-2294 to B.D., J.E.P.-O., E.H. and P.S. Funding was also provided to P.S. by the Swedish Natural Science Research Council (20005471); to J.E.P-O. by the Spanish C.I.C.Y.T. (BIO981316-CE), and to E.H. from Generalitat de Catalunya (1999SGR 00170). 


\section{References}

3 Bartel PL, Chien C, Sternglanz R, Fields S. 1993. Using the two-

4 hybrid system to detect protein-protein interactions. In Cellular

5 Interactions in Development: a Practical Approach, Hartley D

6 (ed.). Oxford University Press: Oxford; 153-179.

7 Bean LE, Dvorachek WH Jr, Braun EL, et al. 2001. Analysis

8 of the $p d x-1$ (snz-1/sno-1) region of the Neurospora crassa

8 genome: correlation of pyridoxine-requiring phenotypes with

9 mutations in two structural genes. Genetics 157: 1067-1075.

10 Begley TP, Downs DM, Ealick SE, et al. 1999. Thiamine

11 biosynthesis in prokaryotes. Arch Microbiol 171: 293-300.

12 Bilski P, Li MY, Ehrenshaft M, Daub ME, Chignell CF. 2000.

12 Vitamin $\mathrm{B}_{6}$ (pyridoxine) and its derivatives are efficient singlet

13 oxygen quenchers and potential fungal antioxidants. Photochem

14 Photobiol 71: 129-300.

15 Blandin G, et al. 2000. Genomic exploration of the Hemias-

16 comycetes yeasts: 4 . The genome of Saccharomyces cerevisiae

17 revisited. FEBS Lett 487: 31-36.

18 Boorstein WR, Ziegelhoffer T, Craig EA. 1994. Molecular evolution of the HSP70 multigene family. J Mol Evol 38: 1-17.

19 Brachmann CB, Davies A, Cost GJ, et al. 1998. Designer deletion

20 strain derived from Saccharomyces cerevisiae S288C: a useful

21 set of strains and plasmids for PCR-mediated gene disruption

22 and other applications. Yeast 14: 115-132.

23 Braun EL, Fuge EK, Padilla PA, Werner-Washburne M. 1996. A

23 stationary-phase gene in Saccharomyces cerevisiae is a member

24 of a novel, highly conserved gene family. J Bacteriol 178:

$25 \quad 6865-6872$.

26 Brookfield JF. 1997. Genetic redundancy. Adv Genet 36: 137-155.

27 Burke D, Dawson D, Stearns T. 2000. Methods in Yeast Genetics.

28 Cold Spring Harbor Laboratory Press: New York.

28 DIP database 2001. http://dip.doe-mbi.ucla.edu/

29 Drewke C, Leistner E. 2001. Biosynthesis of vitamin $\mathrm{B}_{6}$ and

30 structurally related derivatives. Vit Horm 61: 121-155.

31 Durfee T, Becherer K, Chen P-L, et al. 1993. The retinoblastoma

32 protein associates with the protein phosphatase type 1 catalytic subunit. Genes Dev 7: 555-569.

33 Ehrenshaft M, Daub ME. 2001. Isolation of PDX2, a second novel

34 gene in the pyridoxine biosynthesis pathway of eukaryotes,

35 archaebacteria and a subset of eubacteria. J Bacteriol 183:

$36 \quad 3383-3390$

37 Ehrenshaft M, Bilski P, Li MY, Chignell CF, Daub ME. 1999.

38 A highly conserved sequence is a novel gene involved in de

39 novo vitamin $\mathrm{B}_{6}$ biosynthesis. Proc Natl Acad Sci USA 96: 39 9374-9378.

40 Fairhead C, Llorente B, Denis F, Soler M, Dujon B. 1996. New

41 vectors for combinatorial deletions in yeast chromosomes and

42 for gap-repair cloning using 'split-marker' recombination. Yeast

43 12: $1439-1457$

44 Gallego C, Garí E, Colomina N, Herrero E, Aldea M. 1997. The

$44 \mathrm{Cln} 3$ cyclin is downregulated by translational repression and

45 degradation during $\mathrm{G}_{1}$ arrest caused by nitrogen deprivation in

46 budding yeast. EMBO J 16: 7196-7206.

47 Galperin MY. 2001. Conserved 'hypothetical' proteins: new hints

48 and new puzzles. Comp Funct Genom 2: 14-18.

49 Garí E, Piedrafita L, Aldea M, Herrero E. 1997. A set of

49 vectors with a tetracycline-regulatable promoter system for

50 modulated gene expression in Saccharomyces cerevisiae. Yeast

51 13: $837-848$.
Gasch AP, Spellman PT, Kao CM, et al. 2000. Genomic expression programs in the response of yeast cells to environmental changes. Mol Biol Cell 11: 4241-4257. See also http://genome-www.stanford.edu/yeast_stress/.

Goffeau A, Barrell BG, Bussey H. 1996. Life with 6000 genes. Science 274: 563-567.

Hauser NC, Vingron M, Scheideler M, et al. 1998. Transcriptional profiling on all open reading frames of Saccharomyces cerevisiae. Yeast 14: 1209-1221.

Henikoff S, Greene E, Pietrokovski S, Bork P, Attwood TK, Hood L. 1997. Gene families: the taxonomy of protein paralogs and chimeras. Science 278: 609-614.

Hohmann S, Meacock PA. 1998. Thiamine metabolism and thiamine diphosphate-dependent enzymes in the yeast Saccharomyces cerevisiae: genetic regulation. Biochim Biophys Acta 1385: 201-209.

Ito T, Tashiro K, Muta S, et al. 2000. Toward a protein-protein interaction map of the budding yeast: a comprehensive system to examine two-hybrid interactions in all possible combinations between the yeast proteins. Proc Natl Acad Sci USA 97: 1143-1147.

James P, Halladay J, Craig EA. 1996. Genomic libraries and a host strain designed for highly efficient two-hybrid selection in yeast. Genetics 144: 1425-1436.

Llorente B, Fairhead C, Dujon B. 1999. Genetic redundancy and gene fusion in the genome of baker's yeast, Saccharomyces cerevisiae: functional characterization of a three-member gene family involved in the thiamine biosynthetic pathway. $\mathrm{Mol}$ Microbiol 32: 1140-1152.

Matthews CK, Van Holde K, Ahern KG. 2000. Biochemistry, 3rd edn. Addison-Wesley: San Francisco, CA.

Mittenhuber G. 2001. Phylogenetic analyses and comparative genomics of vitamin $\mathrm{B}_{6}$ (pyridoxine) and pyridoxal phosphate biosynthesis pathways. J Mol Microbiol Biotechnol 3: 1-20.

Muhlrad D, Hunter R, Parker R. 1992. A rapid method for localized mutagenesis of yeast genes. Yeast 8: 79-82.

Muller EH, Richards EJ, Norbeck J, et al. 1999. Thiamine repression and pyruvate decarboxylase autoregulation independently control the expression of the Saccharomyces cerevisiae PDC5 gene. FEBS Lett 449: 245-250.

Nishimura H, Kawasaki Y, Kaneko Y, Nosaka K, Iwashima A. 1992. Cloning and characteristics of a positive regulatory gene, THI2 (PHO6), of thiamine biosynthesis in Saccharomyces cerevisiae. FEBS Lett 297: 155-158.

Osmani AH, May GS, Osmani SA. 1999. The extremely conserved pyroA gene of Aspergillus nidulans is required for pyridoxine synthesis and is required indirectly for resistance to photosensitizers. J Biol Chem 274: 23 565-23 569.

Padilla PA, Fuge EK, Crawford ME, Errett A, WernerWashburne M. 1998. The highly conserved, co-regulated SNO and $S N Z$ gene families in Saccharomyces cerevisiae respond to nutrient limitation. J Bacteriol 180: 5718-5726.

Rodríguez-Navarro S, Estruch F, Pérez-Ortín JE. 1999. Functional analysis of 12 ORFs from Saccharomyces cerevisiae chromosome II. Yeast 15: 913-919.

Rubin GM, et al. 2000. Comparative genomics of the eukaryotes. Science 287: 2204-2215.

Seack J, et al. 2001. Identification of highly conserved genes: $S N Z$ and $S N O$ in the marine sponge Suberites domunculata: their gene structure and promoter activity in mammalian cells. Biochim Biophys Acta 1520: 21-24. 
1 Souciet J-L, et al. 2000. Genolevures. FEBS Lett 487: 1-149.

2 Tanaka K, Tazuya K, Yamada K, Kumaoka H. 2000. Biosynthesis

3 of pyridoxine: origin of the nitrogen atom of pyridoxine in microorganisms. J Nutr Sci Vitaminol 46: 55-57.

4 Tanaka K, Tazuya K, Yamada K, Kumaoka H. 2000. Biosynthesis

5 of thiamine under anaerobic conditions in Saccharomyces

6 cerevisiae. Biol Pharm Bull 23: 108-111.

7 Tartof KD. 1975. Redundant genes. Ann Rev Genet 9: 355-385.

8 Tazuya K, Adachi Y, Masuda K, Yamada K, Kumaoka H. 1995.

Origin of the nitrogen atom of pyridoxine in Saccharomyces cerevisiae. Biochim Biophys Acta 1244: 113-116.

10 Thierry A, Dujon B. 1992. Nested chromosomal fragmentation

11 in yeast using the meganuclease I-Sce I: a new method for

12 physical mapping of eukaryotic genomes. Nucleic Acids Res 21: $135625-5631$

13 Uetz $\mathrm{P}$, et al. 2000. A comprehensive analysis of protein-protein

14 interaction in Saccharomyces cerevisiae. Nature 403: 623-627.
See also http://curatools.curagen.com/extpc/com.curagen.portal.servlet.Yeast/

Van Dyck L, Pascual-Ahuir A, Purnelle B, Goffeau A. 1995 An $8.2 \mathrm{~kb}$ DNA segment from chromosome XIV carries the RPD3 and PAS8 genes as well as the Saccharomyces cerevisiae homologue of the thiamine-repressed nmtl gene and a chromosome III-duplicated gene for a putative aryl-alcohol dehydrogenase. Yeast 11: 987-991.

Wach A, Brachat A, Pöhlmann R, Philippsen P. 1994. New heterologous modules for classical or PCR-based gene disruptions in Saccharomyces cerevisiae. Yeast 13: 1793-1808.

Werner-Washburne M, Brown EL, Crawford ME, Peck VM. 1996. Stationary phase in Saccharomyces cerevisiae. Mol Microbiol 19: 1159-1166.
52 53 54 55 56 57 58 59 60 61 62 63 64 65 66 67 68 